\title{
Moringa oleifera Leaves as Eco-Friendly Feed Additive in Diets of Hy-Line Brown Hens during the Late Laying Period
}

\author{
Ahmed A. A. Abdel-Wareth ${ }^{1}$ (D) and Jayant Lohakare ${ }^{2, *}$ \\ 1 Department of Animal and Poultry Production, Faculty of Agriculture, South Valley University, \\ Qena 83523, Egypt; a_bkr1@yahoo.com or a.wareth@agr.svu.edu.eg \\ 2 Department of Agriculture-Animal Science option, University of Arkansas at Pine Bluff, \\ Pine Bluff, AR 71601, USA \\ * Correspondence: lohakarej@uapb.edu; Tel.: +1-870-575-8540; Fax: +1-870-575-4629
}

check for updates

Citation: Abdel-Wareth, A.A.A.; Lohakare, J. Moringa oleifera Leaves as Eco-Friendly Feed Additive in Diets of Hy-Line Brown Hens during the Late Laying Period. Animals 2021, 11, 1116. https://doi.org/10.3390/ ani11041116

Academic Editor: Cormac O'Shea

Received: 3 March 2021

Accepted: 8 April 2021

Published: 13 April 2021

Publisher's Note: MDPI stays neutral with regard to jurisdictional claims in published maps and institutional affiliations.

Copyright: (c) 2021 by the authors. Licensee MDPI, Basel, Switzerland. This article is an open access article distributed under the terms and conditions of the Creative Commons Attribution (CC BY) license (https:/ / creativecommons.org/licenses/by/ $4.0 /)$.
Simple Summary: It is of the utmost importance to explore the merit of a new phytogenic feed additive for sustainable egg production in laying chickens during the late laying period. Thus, the current study was designed to evaluate the effect of the addition of Moringa oleifera leaves to laying hen diets on laying performance, egg quality, excreta ammonia concentrations and blood biochemical parameters. The findings showed that the egg production, weight and mass and eggshell quality of laying hens fed with Moringa oleifera leaves during the late laying period were significantly improved in comparison with those of the hens in the control group. Moringa oleifera leaves supplementation decreased excreta ammonia concentration and serum cholesterol and triglycerides as well as serum liver enzymes, uric acid, and creatinine levels compared to those of the control group.

Abstract: This study investigated the dietary effects of Moringa oleifera leaves supplementation on egg quality, laying performance, excreta ammonia concentrations and serum biochemistry of laying chickens during the late laying period. A total of 240 64-week-old Hy-Line Brown hens were assigned to four treatment diets including Moringa oleifera leaves at 0, 3, 6 or $9 \mathrm{~g} / \mathrm{kg}$, respectively, for eight weeks. The treatments had twelve replicates with five hens each. The results revealed that incremental dietary Moringa oleifera leaves significantly increased $(p<0.01)$ egg weight, production, and mass through 64-68, 68-72 and 64-72 weeks of age. Simultaneously, feed conversion ratio was significantly improved $(p<0.01)$ with Moringa oleifera leaves supplementation compared with the control. Haugh units and the thickness of eggshells significantly improved as a response to diets supplemented with 3,6 and $9 \mathrm{~g} / \mathrm{kg}$ Moringa oleifera leaves at 72 weeks of age. Interestingly, excreta ammonia concentrations, serum cholesterol, aspartate transaminase and alanine aminotransferase significantly decreased by Moringa oleifera leaves supplementation compared with the control group. In conclusion, introducing Moringa oleifera leaves supplementation at 3,6 and $9 \mathrm{~g} / \mathrm{kg}$ increased egg production, eggshell quality, Haugh units, and decreased serum cholesterol, triglycerides, excreta ammonia concentrations besides serum liver enzymes, uric acid and creatinine. Overall, based on the observed results, Moringa oleifera leaves supplementation was very promising and these leaves could be used as an effective feed additive in laying hens' diet during the late laying period.

Keywords: blood biochemicals; egg production; egg quality; laying hens; Moringa oleifera

\section{Introduction}

Natural herbal plants received much more attention as alternative to antibiotics growth promoters in the nutrition of laying hens to improve the egg production. The use of in-feed antibiotics may affect birds, human health, and the environment due to their cross and multiple resistances to bacterial infections in humans. However, it is still a common practice in the Middle East, particularly in Egypt, to add antibiotics as growth promoters to poultry diets to improve their production, health, and egg and meat quality. Phytogenics are one 
of the explored alternatives to feed antibiotics in laying hens because of their antimicrobial and antioxidant activities and positive effects on productive performance [1-3]. Some studies illustrated and proved phytogenic applications in poultry nutrition [4-10] to be beneficial in enhancing productive performances and health status of laying hens. Higher excreta ammonia production reduces the productive and health status of chickens [11,12], increases chicken mortalities by increasing susceptibility of birds to infections [11,13], impair human health and act as a major aerial pollutant [14-16]. An adequate nutritional strategy is necessary to diminish ammonia concentrations and to increase egg production and egg quality in laying hens. Previous studies have demonstrated the suitability of different phytogenics in the nutrition of laying hens $[6,7,10]$, however, information about Moringa as a feed additive in laying hens are insufficient and require further studies.

Moringa oleifera has many common names such as moringa, horseradish tree, drumstick tree, miracle tree, ben oil tree or benzoil tree. Moringa oleifera has a broad use in herbal medicine, believed to be beneficial in immunity enhancement and having antimicrobial and antioxidant traits and a hypo-cholesteremic effect on chickens, mainly due to its nutritional and therapeutic values [17-19]. Briones et al. [20] found that the dietary Moringa leaves supplementation in layers diet can improve production performance and egg quality. Likewise, dietary supplementation of Moringa oleifera at 5\% improved yolk color, albumen height and Haugh unit of eggs [21]. The results of the previous studies in layers using Moringa oleifera could be attributed to dose, feeding duration, composition, processing method, environmental stress aspects or birds' age. Furthermore, it remains vague whether specific effects are resulting from herbal leaves or a synergistic effect due to multiple components [17]. More studies are needed in detecting the optimum levels of Moringa oleifera as feed additive to sustain egg production of laying hens at the late laying period. Therefore, this study was designed to assess the impact of dietary supplementation of different levels of Moringa oleifera leaves on laying performance, egg quality, excreta ammonia concentration and blood biochemical parameters of laying hens in the late laying period.

\section{Materials and Methods}

\subsection{Experimental Birds, Design and Feed Preparation}

A total of 240 (average weight $=1860 \pm 100 \mathrm{~g}$, 64-week-old) Hy-Line Brown hens were assigned to four treatment diets including Moringa oleifera leaves at 0, 3, 6 and $9 \mathrm{~g} / \mathrm{kg}$, respectively, for eight weeks. The required amount of Moringa oleifera leaves were added to a small amount of basal feed and mixed. The mixture was then added to the preset amount of feed for each treatment and mixed thoroughly before being fed to each group. Each treatment had 12 replicates with five hens each.

The hens were kept in 48 cages with $60 \times 60 \times 40 \mathrm{~cm}^{3}$ dimensions. Each cage was provided with feeders and water nipples with a light program of 16 hours of light every day, and the temperature was maintained at approximately $24^{\circ} \mathrm{C}$. Water and feed were provided for ad libitum consumption. The basal diets were calculated according to the breeder's manual for Hy-Line Brown and the recommendations of National Research Council (NRC) [22]. The birds were fed this mash form of diets for 64-72 weeks of age. The basal experimental diet was formulated as in Table 1. 
Table 1. Ingredient composition and chemical analysis of the basal diet (in percent).

\begin{tabular}{cc}
\hline Ingredients & $\%$ \\
\hline Yellow corn & 68.15 \\
Soybean meal 44\% CP & 17.79 \\
Soybean oil & 0.81 \\
Corn gluten 60\% CP & 2.5 \\
Di-calcium phosphate & 1.92 \\
Limestone & 7.97 \\
Premix * & 0.21 \\
Dl-Methionine & 0.25 \\
Choline chloride (50\%) & 0.4 \\
Total & 100 \\
\hline Determined analysis, & $\%$ \\
\hline Dry matter & 89 \\
Ash & 11.8 \\
Crude protein & 18.5 \\
Ether extract & 4.21 \\
Calcium & 3.73 \\
Phosphorus & 0.58 \\
Gross energy (MJ/kg) & 16.3 \\
\hline
\end{tabular}

* The following was appropriated per kg of diet: vitamin A, 12,000 IU; vitamin $\mathrm{D}_{3}, 7200 \mathrm{IU}$; vitamin E, $20 \mathrm{IU}$; vitamin $\mathrm{K}, 3 \mathrm{mg}$; vitamin $\mathrm{B}_{1}$, $833 \mathrm{IU}$; vitamin $\mathrm{B}_{2}, 2000 \mathrm{IU}$; vitamin $\mathrm{B}_{12}, 60 \mathrm{IU}$; pyridoxine, $0.225 \mu \mathrm{g}$; pantothenic acid, $10 \mathrm{mg}$; niacin, $35 \mathrm{mg}$; folic acid, $1.5 \mathrm{mg}$; biotin $125 \mathrm{mg}$; $\mathrm{Mn}, 90 \mathrm{mg}$; $\mathrm{Cu}, 7.5 \mathrm{mg}$; Zn, $65 \mathrm{mg}$; $\mathrm{Fe}, 50 \mathrm{mg}$; Se, $0.1 \mathrm{mg}$.

\subsection{Diet Analysis and Preparation of Dried Moringa oleifera Leaves}

Feed samples were analyzed including moisture (Method Nr. 930.15), ash (Method Nr. 942.05), protein (Method Nr. 984.13), ether extract (Method Nr. 954.02), calcium (Method Nr. 927.02) and phosphorous (Method Nr. 935.59) as described by the AOAC International [23]. The gross energy was determined using adiabatic bomb calorimetry (Parr Instrument Company, Moline, IL, USA). The fresh excreta of each replicate were used for ammonia analysis. Ammonia-N $\left(\mathrm{NH}_{3}-\mathrm{N}\right)$ concentration was estimated by the distillation method according to AOAC [23] on fresh excreta samples. Dried Moringa oleifera leaves were purchased from Qena, Egypt, from a local herbalist. The Moringa oleifera essential oils were extracted by hydro-distillation in a Clevenger-type apparatus for three hours and were used for analysis. The analysis of Moringa oleifera oils took place via a gas chromatography-mass spectrometry instrument [6]. The gas chromatography-mass spectrometry (GC-MS) analysis of the extract was carried out using instrument having a TRACE GC Ultra Gas Chromatographs (THERMO Scientific Corp., USA), coupled with a THERMO mass spectrometer detector (ISQ Single Quadrupole Mass Spectrometer). The GC-MS system was equipped with a TG-5MS column ( $30 \mathrm{~m} \times 0.25 \mathrm{~mm}$ i.d., $0.25 \mu \mathrm{m}$ film thickness). Helium was utilized in the analyses as carrier gas at a flow rate of $1.0 \mathrm{~mL} / \mathrm{min}$ and a split ratio of 1:10 with the following temperature program: $60^{\circ} \mathrm{C}$ for $1 \mathrm{~min}$, rising at $3.0^{\circ} \mathrm{C} / \mathrm{min}$ to $240^{\circ} \mathrm{C}$ and held for $1 \mathrm{~min}$. The injector and detector were held at $240{ }^{\circ} \mathrm{C}$. Diluted samples (1:10 hexane, $v / v)$ of $0.2 \mu \mathrm{L}$ of the mixtures were injected. Mass spectra were obtained by electron ionization (EI) at $70 \mathrm{eV}$, with a spectral range of $\mathrm{m} / \mathrm{z} 40-450$. Most of the compounds were identified with the analytical method: mass spectra (authentic chemicals, Wiley spectral library collection and NSIT library). The active compounds in the Moringa leaves are presented in Table 2. 
Table 2. The main compounds in the Moringa leaves.

\begin{tabular}{ccc}
\hline Retention Time & g/100 g Essential Oil & Compounds \\
\hline 17.75 & 0.71 & thymol \\
25.14 & 1.68 & $\alpha$-curcumene \\
26.17 & 0.40 & $\beta$-bisabolene \\
26.82 & 1.6 & $\beta$-sesquiphellandrene \\
29.05 & 0.45 & caryophyllene oxide \\
29.16 & 1.03 & p-cymene \\
30.14 & 0.94 & trans-nuciferol \\
30.42 & 5.51 & hexacosane \\
31.11 & 0.63 & 7-epi-cis-sesquisabinene hydrate \\
32.55 & 55.46 & Ar-turmerone \\
32.63 & 5.73 & tumerone \\
33.84 & 13.94 & curlone \\
35.33 & 0.89 & heptacosane \\
38.54 & 1.88 & -dodecanone \\
40.93 & 0.97 & farnesyl acetone \\
47.11 & 1.33 & phytol \\
55.76 & 3.23 & 14- $\beta$-H-PREGNA \\
57.28 & 3.62 & tetrapentacontane, $1,54-d i b r o m o$ \\
\hline
\end{tabular}

\subsection{Production Performance Parameters}

During the experimental period, the eggs number and weight from each replicate were measured every day. Egg production was calculated as average hen-day egg production. The consumption of the feed was measured weekly. The Feed conversion ratio (FCR) was calculated as the weight of feed intake divided by egg mass per replicate cage. Egg mass was calculated as: egg weight in grams $\times$ egg production rate. The variables were measured per replicate cage.

\subsection{Egg Quality}

The egg quality parameters were assessed at 68 and 72 weeks of age. A total of 36 eggs during each period per treatment ( 3 eggs per replicate) were used to assess the egg quality on the same day [15]. The collected eggs were weighed and broken onto a glass break-out table for albumen and yolk measurements. The dimensions of yolks and albumen were measured using calipers and weighed. Eggshell weights, albumen and yolk were measured and expressed as percentages of the whole egg's weight. Eggshell thickness (without inner and outer shell membranes) was gauged at the middle of the eggshell using a QCT shell thickness micrometer (Technical Services and Supplies Ltd., England). Haugh Units (HU) was calculated from the records of egg weight $(\mathrm{W})$ and albumen height $(\mathrm{H})$ through the following formula: $\mathrm{HU}=100 \log 10\left(\mathrm{H}-1.7 \mathrm{~W}^{0.37}+7.56\right)$, according to Haugh [24].

\subsection{Blood Sampling and Laboratory Analyses}

After the experimental period, blood samples were collected from the wing vein of 3 birds per replicate (a total of 36 blood samples, per treatment) in tubes to determine the serum biochemical indices such as total cholesterol, triglycerides, liver enzymes such as aspartate transaminase (AST), Alanine aminotransferase (ALT), uric acid and creatinine spectrophotometrically via the matching kits as per the instructions of the manufacturer (Spectrum chemical company, Obour City- Cairo, Egypt).

\subsection{Statistical Analysis}

All analyses were performed using the general linear model (GLM) procedures of SAS 9.2 [25]. The model only included the level of Moringa oleifera leaves supplementation. The cages were the experimental units for all analyses. The impacts of Moringa oleifera levels were analyzed via orthogonal polynomial contrasts for linear and quadratic effects. 
Differences were deemed to be statistically significant at $p<0.05$, and data are expressed as mean and pooled SEM.

\section{Results}

\subsection{Productive Performance and Ammonia Concentrations}

Throughout the experimental period no mortalities were recorded, and the birds were healthy. The incremental dietary Moringa oleifera leaves at 3, 6 and $9 \mathrm{~g} / \mathrm{kg}$ significantly enhanced $(p<0.01)$ egg production, weight and mass compared with the control group during 64-68, 68-72 and 64-72 weeks of age (Table 3). Furthermore, the feed conversion ratio was linearly and quadratically decreased $(p<0.01)$ with the increasing levels of Moringa oleifera leaves at 3,6 and $9 \mathrm{~g} / \mathrm{kg}$ during $64-68,68-72$ and $64-72$ weeks (Table 3 ). Interestingly, excreta ammonia concentrations significantly decreased $(p<0.001)$ due to Moringa oleifera supplementations (Table 3). Within the entire interval of 64-72 weeks, supplementation of Moringa oleifera leaves to laying hens diets at 3,6 and $9 \mathrm{~g} / \mathrm{kg}$ significantly improved $(p<0.001)$ feed conversion ratio by $8.26,12.11$ and $8.83 \%$ in comparison with control, respectively.

Table 3. The effect of Moringa oleifera leaves on the productive performance of laying hens during the late laying period.

\begin{tabular}{|c|c|c|c|c|c|c|c|}
\hline \multirow{2}{*}{ Items } & \multicolumn{4}{|c|}{ Moringa oleifera Leaves $(\mathrm{g} / \mathrm{kg})$} & \multirow{2}{*}{ SEM $^{1}$} & \multicolumn{2}{|c|}{$p$ Value } \\
\hline & 0 & 3 & 6 & 9 & & Linear & Quadratic \\
\hline \multicolumn{8}{|c|}{ 64-68 weeks of age } \\
\hline Egg weight, (g/hen/day) & 60.89 & 63.58 & 64.75 & 63.49 & 0.57 & 0.008 & 0.009 \\
\hline Egg mass, (g/hen/day) & 49.46 & 53.47 & 56.02 & 54.41 & 0.61 & $<0.001$ & 0.002 \\
\hline Hen-day production, $(\%)$ & 81.24 & 84.09 & 86.53 & 85.67 & 0.81 & 0.003 & 0.042 \\
\hline Feed intake, (g/hen/day) & 105.6 & 103.7 & 106.0 & 105.3 & 1.01 & 0.773 & 0.532 \\
\hline Feed conversion ratio & 2.136 & 1.939 & 1.893 & 1.937 & 0.03 & 0.002 & 0.006 \\
\hline \multicolumn{8}{|c|}{$68-72$ weeks of age } \\
\hline Egg weight, (g/hen/day) & 60.89 & 63.23 & 65.92 & 63.98 & 0.42 & $<0.001$ & 0.001 \\
\hline Egg mass, (g/hen/day) & 49.64 & 53.37 & 57.46 & 54.81 & 0.29 & $<0.001$ & 0.001 \\
\hline Hen-day production, $(\%)$ & 81.52 & 84.42 & 87.18 & 85.67 & 0.53 & $<0.001$ & 0.003 \\
\hline Feed intake, (g/hen/day) & 105.7 & 102.6 & 105.3 & 105.0 & 1.08 & 0.894 & 0.252 \\
\hline Feed conversion ratio & 2.128 & 1.923 & 1.833 & 1.916 & 0.02 & 0.001 & 0.001 \\
\hline \multicolumn{8}{|c|}{$64-72$ weeks of age } \\
\hline Egg weight, (g/hen/day) & 61.43 & 63.93 & 65.37 & 64.31 & 0.45 & 0.001 & 0.005 \\
\hline Egg mass, (g/hen/day) & 50.70 & 54.15 & 57.67 & 55.29 & 0.62 & $<0.001$ & 0.002 \\
\hline Hen-day production, $(\%)$ & 82.52 & 84.71 & 88.23 & 85.91 & 0.81 & 0.006 & 0.024 \\
\hline Feed intake, (g/hen/day) & 106.8 & 104.6 & 106.7 & 106.1 & 1.68 & 0.997 & 0.664 \\
\hline Feed conversion ratio & 2.106 & 1.932 & 1.851 & 1.920 & 0.033 & 0.002 & 0.006 \\
\hline Ammonia, g/100 g excreta & 6.044 & 3.919 & 2.743 & 3.585 & 0.266 & $<0.001$ & $<0.001$ \\
\hline
\end{tabular}

${ }^{1}$ SEM: Standard error of the means.

\subsection{Egg Quality}

Table 4 shows the effects of dietary Moringa oleifera leaves supplementation on egg quality. Hens fed Moringa oleifera leaves at levels of 3, 6 and $9 \mathrm{~g} / \mathrm{kg}$ had increased eggshell thickness, eggshell percentage and Haugh units than those fed the control treatment at 68 and 72 weeks of age $(p<0.01)$. However, Moringa oleifera leaves supplementation did not influence other egg quality characteristics like albumen and yolk percentages. 
Table 4. The effect of Moringa oleifera leaves on egg quality of laying hens during the late laying period.

\begin{tabular}{|c|c|c|c|c|c|c|c|}
\hline \multirow{2}{*}{ Items } & \multicolumn{4}{|c|}{ Moringa oleifera Leaves (g/kg) } & \multirow[b]{2}{*}{ SEM $^{1}$} & \multicolumn{2}{|c|}{$p$ Value } \\
\hline & 0 & 3 & 6 & 9 & & Linear & Quadratic \\
\hline \multicolumn{8}{|c|}{68 weeks of age } \\
\hline Haugh units, score & 81.23 & 85.01 & 89.01 & 84.56 & 1.079 & 0.004 & 0.001 \\
\hline Shell thickness (mm) & 0.378 & 0.396 & 0.408 & 0.399 & 0.043 & 0.006 & 0.014 \\
\hline Shell (\%) & 10.75 & 11.62 & 12.84 & 11.64 & 0.382 & 0.028 & 0.061 \\
\hline Albumen (\%) & 62.57 & 61.33 & 60.08 & 60.78 & 0.653 & 0.127 & 0.063 \\
\hline Yolk $(\%)$ & 26.68 & 27.25 & 27.08 & 27.38 & 0.451 & 0.156 & 0.146 \\
\hline \multicolumn{8}{|c|}{72 weeks of age } \\
\hline Haugh units, score & 82.13 & 86.11 & 89.51 & 85.76 & 1.081 & 0.001 & 0.001 \\
\hline Shell thickness (mm) & 0.381 & 0.399 & 0.409 & 0.401 & 0.054 & 0.001 & 0.024 \\
\hline Shell (\%) & 10.85 & 11.73 & 12.88 & 11.74 & 0.883 & 0.013 & 0.032 \\
\hline Albumen (\%) & 62.67 & 61.21 & 60.04 & 60.56 & 0.991 & 0.063 & 0.451 \\
\hline Yolk (\%) & 26.48 & 27.16 & 27.18 & 27.7 & 0.654 & 0.076 & 0.236 \\
\hline
\end{tabular}

${ }^{1}$ SEM: Standard error of the means.

\subsection{Serum Biochemical Parameters}

Table 5 shows the effects of Moringa oleifera leaves supplementation on serum biochemicals. According to the serum metabolic profile, serum cholesterol and triglycerides significantly decreased $(p<0.001)$ with the increase of Moringa oleifera leaves levels in laying hens' diets. Additionally, serum enzymes (AST and ALT) were less $(p<0.001)$ in hens fed Moringa oleifera - supplemented diets. Moreover, serum creatinine and uric acid decreased $(p<0.001)$ in hens fed Moringa oleifera—supplemented diets.

Table 5. The effect of Moringa oleifera leaves on serum metabolic profile of laying hens during the late laying period.

\begin{tabular}{ccccccccc}
\hline \multirow{2}{*}{ Items } & \multicolumn{3}{c}{ Moringa oleifera Leaves $\mathbf{( g / k g )}$} & & \multicolumn{2}{c}{$p$ Value } \\
\cline { 2 - 4 } & $\mathbf{0}$ & $\mathbf{3}$ & $\mathbf{6}$ & $\mathbf{9}$ & & & Linear & Quadratic \\
\hline Cholesterol (mg/dL) & 154.41 & 144.51 & 137.36 & 142.70 & 1.260 & 0.001 & 0.001 \\
Triglycerides (mg/dL) & 138.29 & 128.13 & 124.17 & 128.91 & 0.556 & & 0.001 & 0.004 \\
ALT (U/L) & 29.69 & 25.50 & 21.51 & 22.97 & 0.824 & 0.001 & 0.001 \\
AST (U/L) & 67.79 & 61.56 & 57.01 & 61.19 & 0.992 & & 0.001 & 0.001 \\
Creatinine (mg/dL) & 0.624 & 0.456 & 0.401 & 0.415 & 0.009 & & 0.001 & 0.001 \\
Uric acid (mg/dL) & 4.253 & 3.574 & 2.710 & 3.490 & 0.207 & & 0.001 & 0.001 \\
\hline
\end{tabular}

${ }^{1}$ SEM: Standard error of the means.

\section{Discussion}

Few studies are available in the literature on the application of Moringa oleifera as a potential alternative feed additive for laying hens during the late laying period; therefore, the comparison was made with other studies that used essential oils or herbs. The main determinants of the active components of Moringa oleifera leaves-prior to the addition to the hen diets-could prove useful for insights on its effect on productive performances. In this study, Moringa oleifera leaves' active compounds were consistent with those observed in previous studies $[19,26]$. Furthermore, $\beta$-sitosterol and 4-[ $\alpha$-(L-rhamnosyloxy) benzyl]o-methyl thiocarbamate (trans) are two important active compounds presence in the leaves essential oil of Moringa oleifera that exhibit health-promoting properties [26,27]. Mahfuz and Pioa [27] contributed a review on Moringa oleifera as a natural feed supplement in laying hens' diet. It was concluded that the application of Moringa oleifera in poultry nutrition enhanced the productive performance and health, however, the inclusion levels of Moringa oleifera in poultry diet and their mode of actions are still unclear and need further consideration.

Overall, in the present study, egg production, egg mass and feed conversion ratio improved with the addition of Moringa oleifera leaves to diets, compared with the control group of laying hens. The higher egg weight, mass and production are potentially 
attributed to the specific Moringa oleifera leaves' active components (Table 2). Moreover, the improvements in the egg production could be due to Moringa oleifera leaves' reported antimicrobial and antioxidant properties, and gastro-protective and mucus-enhancing enzyme activities; this is resulting from its essential oil and active components $[18,19,27]$. Similarly, supplementation of Moringa oleifera leaves meal at $10 \mathrm{~g} / \mathrm{kg}$ improved feed conversion ratio and hen-day egg production of laying hens at 55 weeks of age [28], in accordance with the dose and results in our study. On the other hand, the addition of Moringa oleifera at $10 \%$ significantly increased egg production of laying hens [29], a ten-times higher dose than the present study. The hen-day egg production, weight and mass and feed conversion ratio were significantly improved by Moringa oleifera fresh leaves as feed supplement compared with the control group [30]. On the contrary, this study contradicts Ashour et al.'s [31], who reported that dietary supplementations of Moringa oleifera seeds, leaves and their combination did not significantly influence $(p<0.05)$ feed intake, conversion ratio and egg weight compared with the control. Moreover, Olugbemi et al. [32] reported that feed intake, feed conversion ratio egg production was not influenced by the inclusion of $5 \%$ and $10 \%$ Moringa oleifera leaves in laying hen diets. The maximum percentage that was used in our study was $0.9 \%$ far lower than the other reported studies. The inconsistencies in the results of these studies may be due to the use of different bird strains, age, animal production stage, plant parts, agroclimatic conditions, herb compositions, addition levels, application and cultivation methods $[3,5,17]$. There are also studies that used variable doses of supplementation and used plant parts, such as seeds, leaves, extracts, or active compounds. In short, many researchers reported that supplementation levels of Moringa oleifera ranging from $0.5 \%$ up to $10 \%$ could have a positive response in enhancing the productive performance and health status of laying hens [28-30]. Further studies are still needed to determine the optimal level of supplementation that increase productive performance in chickens, considering the economic benefits and health status.

Ammonia is derived from the degradation of nitrogenous feed ingredients and is a colorless gas with pungent odor. Ammonia is considered as one of the harmful gases as it has negative effects on poultry including increased susceptibility to respiratory diseases and therefore reduced productive performance, besides poses a threat to the workers' health. In the current study, excreta ammonia concentrations significantly decreased with the increasing levels of Moringa oleifera leaves supplementation. The phytogenic functions might have stimulated the intestinal enzyme activity, reduced pathogenic bacteria, increased nitrogen absorption and controlled secretion of odor and ammonia content [33]. Moreover, Hong et al. [34] reported that ileal ammonia concentration was significantly decreased in broiler chickens fed $125 \mathrm{mg} / \mathrm{kg}$ essential oil (essential oil derived from oregano, anise, and citrus peel). Supplementation of $100 \mathrm{mg} / \mathrm{kg}$ of yucca in the laying-hen diet significantly reduced ammonia generation and emission in laying-hen barns [35].

Egg quality is considered as one of the most important criteria in the egg industry, influencing economic profitability. Hens fed Moringa oleifera leaves at 3,6 and $9 \mathrm{~g} / \mathrm{kg}$ had increased eggshell thickness, percentage and Haugh units compared to those ingesting the control treatment at 68 and 72 weeks of age (Table 4). It may be hypothesized that Moringa oleifera allows increased eggshell weight and thickness due to the phytogenic compounds that may have the ability to improve calcium storage, uterine functions and intestinal secretions, which could lead to improving eggshell and egg quality $[10,36]$. Furthermore, the eggshell and Haugh units are vital for the egg industry and are considered as signs of egg freshness and optimal shelf life [6,37,38]. The active components of Moringa oleifera leaves seem to improve oviposition and uterine health, thus improving egg quality. In accordance with our results, Briones et al. [20] stated that Moringa oleifera leaves can be supplemented to layers' diets to improve egg quality. Ahmad et al. [39] also reported that supplementation of Moringa oleifera leaves at 5,10 and $15 \mathrm{~g} / \mathrm{kg}$ significantly increased Haugh units and eggshell thickness of laying hens, from 50-66 weeks of age. In contrast, Abou-Elezz et al. [30] surmised that Moringa oleifera leaves in diets did not affect egg quality parameters, including shell percent and thickness. 
Since the studies on this subject are few, the full comprehension and discussion of physiological responses of laying hens to Moringa oleifera leaves are hindered. In the current study, Moringa oleifera leaves have shown important impacts on serum cholesterol, triglycerides, AST, ALT, creatinine and uric acid of laying hens during the late laying period; however, the exact mechanism of Moringa leaves on blood metabolic profiles are not known yet [40]. The serum values of the measured biochemicals are within the normal physiological range [21,38,41,42]. Furthermore, Ghasi et al. [43] reported that Moringa oleifera leaves have hypo-cholesterolemic functions. Moringa oleifera leaves exhibit cholesterol-lowering activities affected by the active compounds present in them and these compounds could decrease the intestine dietary cholesterol uptake [44,45]. Supplementation of Moringa oleifera leaves to broiler diets significantly lowered serum cholesterol contents [46,47]. Ahmad et al. [39] reported that supplementation of Moringa oleifera leaves at 5,10 and $15 \mathrm{~g} / \mathrm{kg}$ significantly lowered serum cholesterol and uric acid of laying hens, from 50-66 weeks of age. In the current study, hens fed a diet supplemented with Moringa oleifera leaves had significantly reduced serum AST, ALT, uric acid and creatinine compared with the control group (Table 5), considered as a positive sign of the liver and kidney's synthetic functions and laying hens' health during the late period. For liver functions, ALT and AST are the most widely used clinical biomarkers for hepatic health and leakage of ALT and AST from the hepatocytes into the blood occurs following hepatocellular injury and their levels usually rise whenever the liver is being damaged [47]. Therefore, it could be reported that supplementation of Moringa oleifera leaves promote liver health by decreasing serum ALT and AST concentrations in laying hens. These results concur with Halaby et al. [48] who reported that Moringa oleifera leaves significantly decreased serum uric acid and creatinine in rats more than that of the positive control group. Supplementation of Moringa oleifera leaves at 0.5, 1.0, 1.5 and 2.0\% induced a mild reduction in cholesterol and uric acid, AST and ALT in broiler chickens [49], implicating that there was no liver damage. Contrarily, laying hens fed the diets containing 15\% Moringa oleifera leaves showed surged AST activity more than those fed the control diet [21]. Multiple reports disagree on the influence of supplemental Moringa oleifera on liver and kidney functions, which could be due to the concentration of the active substances in their Moringa sources. Further studies focusing on the actual mechanisms of the active compounds are warranted.

\section{Conclusions}

In conclusion, Moringa oleifera leaves supplementation at 3, 6 and $9 \mathrm{~g} / \mathrm{kg}$ increased egg production, eggshell quality, Haugh units, and decreased serum cholesterol, triglycerides, excreta ammonia concentrations besides serum liver enzymes, uric acid and creatinine, and could be used as an effective feed additive in laying hens' diet during the late laying period. Further studies are still needed to elucidate the exact mechanism of action of Moringa leaves and their essential oils and to specify the effective dose in poultry nutrition.

Author Contributions: Conceptualization, A.A.A.A.-W.; data curation, A.A.A.A.-W.; statistical analysis, J.L.; methodology, A.A.A.A.-W.; writing—original draft, A.A.A.A.-W.; writing-review and editing, J.L. All authors have read and agreed to the published version of the manuscrip.

Funding: This research received no external funding.

Institutional Review Board Statement: The procedures used were approved by the Authors' institution (Department of Animal and Poultry Production, South Valley University, Egypt) Ethics Committee (No. 34/2019), and care was taken to minimize the number of animals used.

Data Availability Statement: Data presented in this study are available on fair request from the respective author.

Conflicts of Interest: The authors declare no conflict of interest. 


\section{References}

1. Laptev, G.Y.; Yildirim, E.A.; Ilina, L.A.; Filippova, V.A.; Kochish, I.I.; Gorfunkel, E.P.; Dubrovin, A.V.; Brazhnik, E.A.; Narushin, V.G.; Novikova, N.I.; et al. Effects of essential oils-based supplement and salmonella infection on gene expression, blood parameters, cecal microbiome, and egg production in laying hens. Animals 2021, 11, 360. [CrossRef]

2. Rabelo-Ruiz, M.; Ariza-Romero, J.J.; Zurita-González, M.J.; Martín-Platero, A.M.; Baños, A.; Maqueda, M.; Valdivia, E.; MartínezBueno, M.; Peralta-Sánchez, J.M. Allium-Based phytobiotic enhances egg production in laying hens through microbial composition changes in ileum and cecum. Animals 2021, 11, 448. [CrossRef] [PubMed]

3. Abdel-Wareth, A.A.A.; Kehraus, S.; Südekum, K.-H. Peppermint and its respective active component in diets of broiler chickens: Growth performance, viability, economics, meat physicochemical properties, and carcass characteristics. Poult. Sci. 2019, 98, 3850-3859. [CrossRef] [PubMed]

4. Tufarelli, V.; Baghban-Kanani, P.; Azimi-Youvalari, S.; Hosseintabar-Ghasemabad, B.; Slozhenkina, M.; Gorlov, I.; Seidavi, A.; Ayaşan, T.; Laudadio, V. Effects of Horsetail (Equisetum arvense) and Spirulina (Spirulina platensis) Dietary supplementation on laying hens productivity and oxidative status. Animals 2021, 11, 335. [CrossRef]

5. Abdel-Wareth, A.A.A.; Metwally, A.E. Productive and physiological response of male rabbits to dietary supplementation with thyme essential oil. Animals 2020, 10, 1844. [CrossRef] [PubMed]

6. Abdel-Wareth, A.A.A.; Lohakare, J.D. Effect of dietary supplementation of peppermint on performance, egg quality, and serum metabolic profile of Hy-Line Brown hens during the late laying period. Anim. Feed Sci. Technol. 2014, 197, 114-120. [CrossRef]

7. Abdel-Wareth, A.A.A. Effect of dietary supplementation of thymol, synbiotic and their combination on performance, egg quality and serum metabolic profile of Hy- Line Brown hens. Br. Poult. Sci. 2016, 57, 114-122. [CrossRef] [PubMed]

8. Brenes, A.; Roura, E. Essential oils in poultry nutrition: Main effects and modes of action. Anim. Feed Sci. Technol. 2010, 158, 1-14. [CrossRef]

9. Lee, K.-W.; Everts, H.; Kappert, H.J.; Van der Kuilen, J.; Lemmers, A.G.; Frehner, M.; Beynen, A.A. Growth performance, intestinal viscosity, fat digestibility and plasma cholesterol in broiler chickens fed a rye-containing diet without or with essential oil components. Int. J. Poult. Sci. 2004, 3, 613-618.

10. Liu, M.; Lu, Y.; Gao, P.; Xie, X.; Li, D.; Yu, D.; Yu, M. Effect of curcumin on laying performance, egg quality, endocrine hormones, and immune activity in heat-stressed hens. Poult. Sci. 2020, 99, 2196-2202. [CrossRef]

11. Ahmed, S.T.; Islam, M.; Mun, H.-S.; Sim, H.-J.; Kim, Y.-J.; Yang, C.-J. Effects of Bacillus amyloliquefaciens as a probiotic strain on growth performance, cecal microflora, and fecal noxious gas emissions of broiler chickens. Poult. Sci. 2014, 93, $1963-1971$. [CrossRef]

12. Wang, H.; Ni, X.; Qing, X.; Liu, L.; Xin, J.; Luo, M.; Khalique, A.; Dan, Y.; Pan, K.; Jing, B.; et al. Probiotic Lactobacillus johnsonii BS15 Improves blood parameters related to immunity in broilers experimentally infected with subclinical necrotic enteritis. Front. Microbiol. 2018, 9, 49. [CrossRef]

13. Kristensen, H.H.; Wathes, C.M. Ammonia and poultry welfare: A review. World's Poult. Sci. J. 2000, 56, 235-245. [CrossRef]

14. Ferket, P.R.; van Heugten, E.; van Kempen, T.A.T.G.; Angel, R. Nutritional strategies to reduce environmental emissions from nonruminants. J. Anim. Sci. 2002, 80, E168-E182. [CrossRef]

15. Park, J.W.; Jeong, J.S.; Lee, S.I.; Kim, I.H. Effect of dietary supplementation with a probiotic (Enterococcus faecium) on production performance, excreta microflora, ammonia emission, and nutrient utilization in ISA brown laying hens. J. Appl. Poult. Res. 2016, 95, 2829-2835. [CrossRef] [PubMed]

16. Ushida, K.; Hashizume, K.; Miyazaki, K.; Kojima, Y.; Takakuwa, S. Isolation of Bacillus SP. as a volatile sulfur-degrading bacterium and its application to reduce the fecal odor of pig. Asian Aust. J. Anim. Sci. 2003, 16, 1795-1798. [CrossRef]

17. Hippenstiel, F.; Abdel-Wareth, A.A.A.; Kehraus, S.; Südekum, K.-H. Effects of selected herbs and essential oils, and their active components on feed intake and performance of broilers-A review. Arch. Fur Geflugelkunde 2011, 75, $226-234$.

18. Makkar, H.P.S.; Becker, K. Nutritional value and antinutritional components of whole and ethanol extract of Moringa oleifera leaves. Anim. Feed Sci. Technol. 1996, 63, 211-228. [CrossRef]

19. Marrufo, T.; Nazzaro, F.; Mancini, E.; Fratianni, F.; Coppola, R.; Martino, L.D.; Agostinho, A.B.; Feo, V.D. Chemical composition and biological activity of the essential oil from leaves of Moringa oleifera Lam. cultivated in Mozambique. Molecules 2013, 18, 10989-11000. [CrossRef]

20. Briones, J.; Leung, A.; Bautista, N.; Golin, S.; Caliwag, N.; Carlos, M.A.; Guevarra, J.; Miranda, J.; Guevarra, J.K.; Pili, N.L.; et al. Utilization of Moringa oleifera Lam. in animal production. Acta Hortic. 2017, 1158, 54. [CrossRef]

21. Lu, W.; Wang, J.; Zhang, H.J.; Wu, S.G.; Qi, G.H. Evaluation of Moringa oleifera leaf in laying hens: Effects on laying performance, egg quality, plasma biochemistry and organ histopathological indices. Ital. J. Anim. Sci. 2016, 15, 658-665. [CrossRef]

22. NRC [National Research Council]. Nutrient Requirements of Poultry, 9th revised ed.; National Academic Press: Washington, DC, USA, 1994; p. 155.

23. AOAC International. Official Methods of Analysis, 18th ed.; American Association of Official Analytical Chemists: Arlington, TX, USA, 2006.

24. Haugh, R.R. The Haugh unit for measuring egg quality. U. S. Egg Poult. Mag. 1937, 43, 552-555.

25. SAS Institute. User's Guide: Statistics. Version 9.2; SAS Institute, Inc.: Cary, NC, USA, 2009.

26. Shousha, W.G.; Aboulthana, W.M.; Salama, A.H.; Saleh, M.H.; Essawy, E.A. Evaluation of the biological activity of Moringa oleifera leaves extract after incorporating silver nanoparticles, in vitro study. Bull. Natl. Res. Cent. 2019, 43, 212. [CrossRef] 
27. Mahfuz, S.; Piao, X.S. Application of Moringa (Moringa oleifera) as natural feed supplement in poultry diets. Animals 2019, 9, 431. [CrossRef]

28. Voemesse, K.; Teteh, A.; Nideou, D.; N'nanle, O.; Gbeassor, M.; Decuypere, E.; Tona, K. Effect of Moringa oleifera leaf meal on growth performance and blood parameters of egg type chicken during juvenile growth. Int. J. Poult. Sci. 2018, 17, 154-159. [CrossRef]

29. Moreki, J.C.; Gabanakgosi, K. Potential use of Moringa oleifera in poultry diets. Glob. J. Anim. Sci. Res. 2014, 2, 109-115.

30. Abou-Elezz, F.M.K.; Sarmiento-Franco, L.; Santos-Ricalde, R.; Solorio-Sanchez, J.F. The nutritional effect of Moringa oleifera fresh leaves as feed supplement on Rhode Island Red hen egg production and quality. Trop. Anim. Health Prod. 2012, 44, 1035-1040. [CrossRef]

31. Ashour, E.A.; El-Kholy, M.S.; Alagawany, M.; Abd El-Hack, M.E.; Mohamed, L.A.; Taha, A.E.; El Sheikh, A.I.; Laudadio, V.; Tufarelli, V. Effect of dietary supplementation with Moringa oleifera leaves and/or seeds powder on production, egg characteristics, hatchability, and blood chemistry of laying Japanese quails. Sustainability 2020, 12, 2463. [CrossRef]

32. Olugbemi, T.S.; Mutayoba, S.K.; Lekule, F.P. Evaluation of Moringa oleifera leaf meal inclusion in cassava chip-based diets fed to laying birds. Livest. Res. Rural Dev. 2010, 22, 27-37.

33. Sethiya, N.K. Review on natural growth promoters available for improving gut health of poultry: An alternative to antibiotic growth promoters. Asian J. Poult. Sci. 2016, 10, 1-29. [CrossRef]

34. Hong, J.-C.; Steiner, T.; Aufy, A.; Lien, T.-F. Effects of supplemental essential oil on growth performance, lipid metabolites and immunity, intestinal characteristics, microbiota and carcass traits in broilers. Livest. Sci. 2012, 144, 253-262. [CrossRef]

35. Chepete, H.J.; Xin, H.; Mendes, L.B.; Li, H.; Bailey, T.B. Ammonia emission and performance of laying hens as affected by different dosages of Yucca schidigera in the diet. J. Appl. Poult. Res. 2012, 21, 522-530. [CrossRef]

36. Nadia, L.R.; Hassan, R.A.; Qota, E.; Fayek, H. Effect of natural antioxidant on oxidative stability of eggs and productive and reproductive performance of laying hens. Int. J. Poult. Sci. 2008, 7, 134-150. [CrossRef]

37. Özek, K.; Wellmann, K.T.; Ertekin, B.; Tarim, B. Effects of dietary herbal essential oil mixture and organic acid preparation on laying traits, gastro-intestinal tract characteristics, blood parameters and immune response of laying hens in a hot summer season. J. Anim. Feed Sci. 2011, 20, 575-586. [CrossRef]

38. Williams, K.C. Some factors affecting albumen quality with particular reference to Haugh unit score. World's Poult. Sci. J. 1992, 48, 5-16. [CrossRef]

39. Ahmad, S.; Khalique, A.; Pasha, T.N.; Mehmood, S.; Hussain, K.; Ahmad, S.; Shaheen, M.S.; Naeem, M.; Shafiq, M. Effect of Moringa oleifera (Lam.) pods as feed additive on egg antioxidants, chemical composition and performance of commercial layers South Afr. J. Anim. Sci. 2017, 47, 864-873. [CrossRef]

40. Gupta, A.; Gautam, M.K.; Singh, R.K.; Kumar, M.V.; Rao, C.V.; Goel, R.K.; Anupurba, S. Immunomodulatory effect of Moringa oleifera Lam. extract on cyclophosphamide induced toxicity in mice. Indian J. Exp. Biol. 2010, 48, 1157-1160. [PubMed]

41. Azzam, M.M.M.; Dong, X.Y.; Xie, P.; Wang, C.; Zou, X.T. The effect of supplemental l-threonine on laying performance, serum free amino acids, and immune function of laying hens under high-temperature and high-humidity environmental climates. $J$. Appl. Poult. Res. 2011, 20, 361-370. [CrossRef]

42. Bozkurt, M.; Hippenstiel, F.; Abdel-Wareth, A.A.A.; Kehraus, S.; Küçükyilmaz, K.; Südekum, K.-H. Effects of selected herbs and essential oils on performance, egg quality and some metabolic activities in laying hens-A review. Euro. Poult. Sci. $2014,78,15$.

43. Ghasi, S.; Nwobodo, E.; Ofilis, J.O. Hypocholesterolemic effects of crude extract of the leaf of Moringa oleifera Lam in high-fat diet fed Wistar rats. J. Ethnopharmacol. 2000, 69, 21-25. [CrossRef]

44. Maheshwari, K.; Yadav, R.K.; Malhotra, J.; Dhawan, N.G.; Mohan, L. Fascinating nutritional, prophylactic, therapeutic and socio-economic reconcile attributable to drum stick tree (Moringa oleifera Lam.). Glob. J. Med. Res. B Pharm. Drug Discov. Toxicol. Med. 2014, 14, 11-22.

45. Jain, P.G.; Patil, S.D.; Haswani, N.G.; Girase, M.V.; Surana, S.J. Hypolipidemic activity of Moringa oleifera Lam., Moringaceae, on high fat diet induced hyperlipidemia in albino rats. Rev. Bras. Framacogn. 2010, 20, 969-973. [CrossRef]

46. Alnidawi, A.; Ali, F.; Abdelgayed, S.; Ahmed, F.; Farid, M. Moringa oleifera leaves in broiler diets: Effect on chicken performance and health. Food Sci. Qual. Manag. 2016, 58, 40-48.

47. Enemor, V.H.A.; Anosike, J.C.; Nwoke, B.E.B.; Chikezie, P.C. Serum aminotransferase and bilirubin levels in malaria patients. Int. J. Nat. Appl. Sci. 2005, 1, 85-89. [CrossRef]

48. Halaby, M.S.; Elmetwaly, M.M.; Omar, A.A.A. Effect of Moringa Oleifera on serum lipids and kidney function of hyperlipidemic rats. J. Appl. Sci. Res. 2013, 9, 5189-5198.

49. Divya, A.B.; Mandal, A.; Biswas, A.; Yadav, A.S.; Biswas, A.K. Effect of dietary Moringa oleifera leaves powder on growth performance, blood chemistry, meat quality and gut microflora of broiler chicks. Anim. Nutr. Feed Tech. 2014, 14, 349-357. [CrossRef] 